\title{
Differences in Pop Levels between Conventional and Omega-3 Fatty Acid-Enriched Milk and Dairy Products
}

\author{
Cristiana Guerranti and Silvano Ettore Focardi \\ Department of Environmental Sciences “G. Sarfatti”, University of Siena, Via Mattioli 4, 53100 Siena, Italy \\ Correspondence should be addressed to Cristiana Guerranti, guerranticri@unisi.it
}

Received 1 April 2011; Accepted 11 May 2011

Academic Editors: W. G. Foster, A. H. Milton, P. Urban, and S. M. Waliszewski

Copyright ( $) 2011$ C. Guerranti and S. E. Focardi. This is an open access article distributed under the Creative Commons Attribution License, which permits unrestricted use, distribution, and reproduction in any medium, provided the original work is properly cited.

\begin{abstract}
Conventional and omega-3 fatty acid-enriched milk and cheese were analyzed for persistent organic pollutants (POPs). Omega3 -enriched products are usually supplemented with fish oil which is potentially contaminated. All classes of the considered POPs (PCBs, DDT, HCB, PBDEs, and PCDD/Fs) were found in the samples, with average concentrations higher in omega-3-enriched products than in conventional ones. For PCBs, DDT, and HCB, differences were statistically significant and, therefore, cannot be ascribed to normal variability. With regard to all classes of compounds, the highest levels in individual samples were always found in omega-3 products, in line with the hypothesis that these foods are potentially more contaminated than conventional ones.
\end{abstract}

\section{Introduction}

Persistent organic pollutants (POPs) are a large class of organic contaminants that pose potential risks for human health [1]. Since they are highly lipophilic and resist transformation, they bioaccumulate in animal and human adipose tissue [2]. Food is considered the main source of nonoccupational human exposure to most organohalogen compounds; indeed, foodstuffs of animal origin, especially meat, dairy, and fish products, contribute more than $90 \%$ of the human body burden [3]. Moderate to high levels of POPs are normally encountered in milk and dairy products because lactating animals eliminate lipophilic organohalogen compounds from their fatty tissue through milk production [2]. Dairy products are usually high in fat and may, therefore, contain large quantities of lipophilic contaminants.

Consumption of milk and dairy products supplemented with omega-3 fatty acids is advertised as beneficial for health. However, the purported benefits of these products, borderline between food and drugs, are often based more on ideological and emotional factors than on complete scientific research. Omega-3-enriched products may not be as beneficial as they are claimed to be. Enriched products are usually supplemented with fish oil, which besides being a good source of high-quality proteins, minerals, vitamins, and polyunsaturated omega-3 fatty acids, is extracted from fish, products potentially very contaminated by compounds such as pesticides and dioxins [3].

In this study we analyzed samples of conventional and omega-3-enriched milk and cheese for POPs levels.

\section{Materials and Methods}

Analysis of two chlorinated pesticides (HCB and DDTs), 19 PBDE, seven PCDDs, ten PCDFs, and 57 PCBs was performed on 30 pools of milk and cheese acquired from three supermarkets in central Italy. The pools consisted of small portions of the different foods purchased, typically four or five samples, often of the same product differently packaged. They were placed in containers decontaminated with acetone and n-hexane and stored at $-20^{\circ} \mathrm{C}$ until analysis.

PCB congeners (IUPAC numbers CB18, CB22, CB26, CB28, CB31, CB33, СB40, CB42, CB44, CB49, CB52, CB77, CB81, CB95, СB99, CB101, CB105, CB110, CB114, CB118, CB123, CB126, CB128, CB134, CB136, CB137, CB138, CB141, CB146, CB149, CB151, CB153, CB156, CB157, CB158 CB167, CB169, CB170, CB171, CB172, CB174, CB176, CB177, CB178, CB180, CB183, CB185, CB187, CB189, CB194, CB195, CB196, CB199, CB201, 
CB202, CB205, CB206, and CB207) and PBDEs (IUPAC numbers BDE3, BDE7, BDE5, BDE17, BDE28, BDE49, BDE71, BDE47, BDE66, BDE77, BDE100, BDE119, BDE99, BDE85, BDE126, BDE154, BDE153, BDE138, and BDE156), were selected on the basis of their presence in commercial mixtures, the environment, and body tissues. Throughout the paper PCBs and PBDEs are represented by their IUPAC numbers. The seventeen PCDD and PCDF congeners analyzed were those substituted in positions $2,3,7$, and 8 .

2.1. Chemical Analysis. Analysis of samples was done following the method proposed by Corsolini et al. [4] with some modifications. To extract and purify organohalogen compounds from solid samples, the products were reduced to small pieces and homogenized with a Buchi Mixer at the time of analysis. An aliquot of fresh sample (about $10 \mathrm{~g}$ ) was dehydrated with anhydrous sodium sulphate, spiked with internal standard containing PCB 30, PCB 209, and PBDE $139{ }^{13} \mathrm{C}$ (supplied by Supelco and Cambridge Isotope Laboratories, respectively) and a mixture of $\mathrm{PCDD} / \mathrm{DF}{ }^{13} \mathrm{C}$ (Cambridge Isotope Laboratories) as envisaged by EPA quantification method 1613, and digested in a Soxhlet apparatus with dichloromethane and n-hexane $(3: 1)$ at $120^{\circ} \mathrm{C}$ for $16 \mathrm{~h}$. An aliquot of the extract (about 10\%) was used to determine lipid content by gravimetry. The remaining aliquot was concentrated to $10 \mathrm{~mL}$ in a rotary evaporator and eluted with n-hexane on a chromatograph column packed with 100-200 mesh nonactivated silica gel and acidified silica gel $\left(40 \% \mathrm{H}_{2} \mathrm{SO}_{4}, 60 \%\right.$ silica gel). The eluate was concentrated in a rotary evaporator and placed in vials for gas chromatography. If the sample was visibly still fatty after silica-gel column purification, it was cleaned up with sulphuric acid.

Milk samples were freeze-dried before Soxhlet extraction and after silica column chromatography, and if they were still too fatty to concentrate, they were washed with a small volume of sulphuric acid in the test tube.

The resulting extracts were used for the determination of chlorinated pesticides, PBDE, and total PCBs.

A Perkin Elmer Autosystem gas chromatograph with $\mathrm{Ni}^{63}$ electron capture detector and a Supelco SBP-5, bound phase fused silica capillary column (length $30 \mathrm{~m}$, i.d. $0.2 \mathrm{~mm}$, film thickness $125 \mu \mathrm{m}$ ) was used for PCB and pesticide analyses. The carrier gas was helium at 15.5 psi; the scavenger gas was argon/methane (95/5). The split-splitless injector was used in splitless mode at a temperature of $270^{\circ} \mathrm{C}$. Detector temperature was $300^{\circ} \mathrm{C}$. The oven programme was $120^{\circ} \mathrm{C}$ for $1 \mathrm{~min}$, to $180^{\circ} \mathrm{C}$ at $25^{\circ} \mathrm{C} / \mathrm{min}$, to $280^{\circ} \mathrm{C}$ at $5^{\circ} \mathrm{C} / \mathrm{min}$, and hold for $10 \mathrm{~min}$. Contaminants were determined by comparing the results with those of external standards of known concentration and composition and at least $99 \%$ purity:

(i) Aroclor 1260 (Supelco Inc., US EPA-certified),

(ii) mixtures of various mono-ortho-PCB congeners (Dr. Ehrenstorfer $\mathrm{GmbH}$ ),

(iii) a mixture of HCB and DDT isomers and congeners (Dr. Ehrenstorfer GmbH).
PBDEs were identified and quantified using a Trace GC 2000/Polaris ion trap mass spectrometer equipped with an AS2000 autosampler (ThermoFinnigan) and a Restek Rtx$5 M S$ capillary column $(30 \mathrm{~m}$, i.d. $0.25 \mathrm{~mm}$, film thickness $0.25 \mu \mathrm{m})$. A $2 \mu \mathrm{L}$ aliquot of sample in isooctane was injected in splitless mode with helium as carrier gas. Injector temperature was $275^{\circ} \mathrm{C}$. The ramp program was $80^{\circ} \mathrm{C}$ for $2 \mathrm{~min}$, to $200^{\circ} \mathrm{C}$ at $25^{\circ} \mathrm{C} / \mathrm{min}$, to $300^{\circ} \mathrm{C}$ at $4^{\circ} \mathrm{C} / \mathrm{min}$, and hold $10 \mathrm{~min}$. Excitation voltages were $4.75 \mathrm{~V}$ for tri- and tetraBDEs, $4.60 \mathrm{~V}$ for penta-BDEs, and $4.70 \mathrm{~V}$ for hexa-BDEs. The internal standard was $\mathrm{PCB} 14{ }^{13} \mathrm{C}$ in isooctane (Cambridge Isotope Laboratories), and the PBDE standard solution for calibration was from Wellington Laboratories Inc.

To analyse non-ortho-PCBs $77,81,126$, and 169, furans, and dioxins, the rest of the extract was concentrated and run on a silica-impregnated activated carbon chromatograph column (Wako). The column (i.d. $10 \mathrm{~mm}$ ) was packed with sodium sulphate and $1 \mathrm{~g}$ activated carbon. The first elution was with hexane, followed by elution of the sample extract, then another elution with hexane. The eluate of these phases was discarded. The eluate of a final elution with toluene was collected and concentrated in a rotary evaporator for analytical determination.

Non-ortho PCBs were analysed by mass spectrometry using a spectrometer with Finnigan Polaris $Q$ ion trap detector coupled with a Trace GC Ultra chromatograph with AI3000 automatic sampler (ThermoFinnigan) and a Restek Rtx-5MS capillary column $(30 \mathrm{~m} \times 0.25 \mathrm{~mm}$, i.d. $0.5 \mu \mathrm{m})$. To determine coplanar PCBs, $2 \mu \mathrm{L}$ of each sample extract was injected in splitless mode at $250^{\circ} \mathrm{C}$. Oven temperature was $110^{\circ} \mathrm{C}$ for $1 \mathrm{~min}$, to $220^{\circ} \mathrm{C}$ at $20^{\circ} \mathrm{C} / \mathrm{min}$, hold $2 \mathrm{~min}$, to $300^{\circ} \mathrm{C}$ at $10^{\circ} \mathrm{C} / \mathrm{min}$, and hold $5 \mathrm{~min}$. Molecular ionisation was obtained by electronic impact, and scans were performed in MS/MS mode with an excitation voltage of $6.60 \mathrm{~V}$. A mixture of four non-ortho PCBs at five concentrations supplied by AccuStandard Inc. was used to plot the calibration curve.

PCDD and PCDF were determined by EPA method 1613 according to the European Community directive 2002/69/CE. $2 \mu \mathrm{L}$ of each sample extract, brought to final volume with the recovery standard specified by EPA 1613, was injected in splitless mode at $250^{\circ} \mathrm{C}$. Oven temperature was $110^{\circ} \mathrm{C}$ for $1 \mathrm{~min}$, to $220^{\circ} \mathrm{C}$ at $20^{\circ} \mathrm{C} / \mathrm{min}$, hold $2 \mathrm{~min}$, to $300^{\circ} \mathrm{C}$ at $10^{\circ} \mathrm{C} / \mathrm{min}$, and hold $5 \mathrm{~min}$. Molecular ionisation was obtained by electronic impact, and scans were performed in MS/MS mode. Excitation voltages were $4.40 \mathrm{~V}$ for tetra-, penta-, and hexa-CDD, $4.50 \mathrm{~V}$ for hepta-CDD, $4.75 \mathrm{~V}$ for tetra-CDF, $4.90 \mathrm{~V}$ for octa-CDD, $5.05 \mathrm{~V}$ for penta-CDF, $5.30 \mathrm{~V}$ for hexa-CDF, and $5.50 \mathrm{~V}$ for hepta- and octa$\mathrm{CDF}$. A mixture of $\mathrm{PCDD} / \mathrm{F}$ at five concentrations from AccuStandard Inc. was used for the calibration curve.

The limits of detection (LOD) of the compounds were the concentrations detected in blanks $+3 \mathrm{SD}$ and on the average were $0.01 \mathrm{ng} / \mathrm{g}$ for PCB congeners, $\mathrm{HCB}$, and DDTs, $0.02 \mathrm{pg} / \mathrm{g}$ for PBDE congeners, and $0.5 \mathrm{pg} / \mathrm{g}$ for PCDD/F congeners.

Results (lipid basis) of pairs of food groups were compared using the Mann-Whitney-Wilcoxon nonparametric test. Statistical analysis was run with the programmes Microsoft Excel 2003 (Microsoft Corporation) and Statistica 


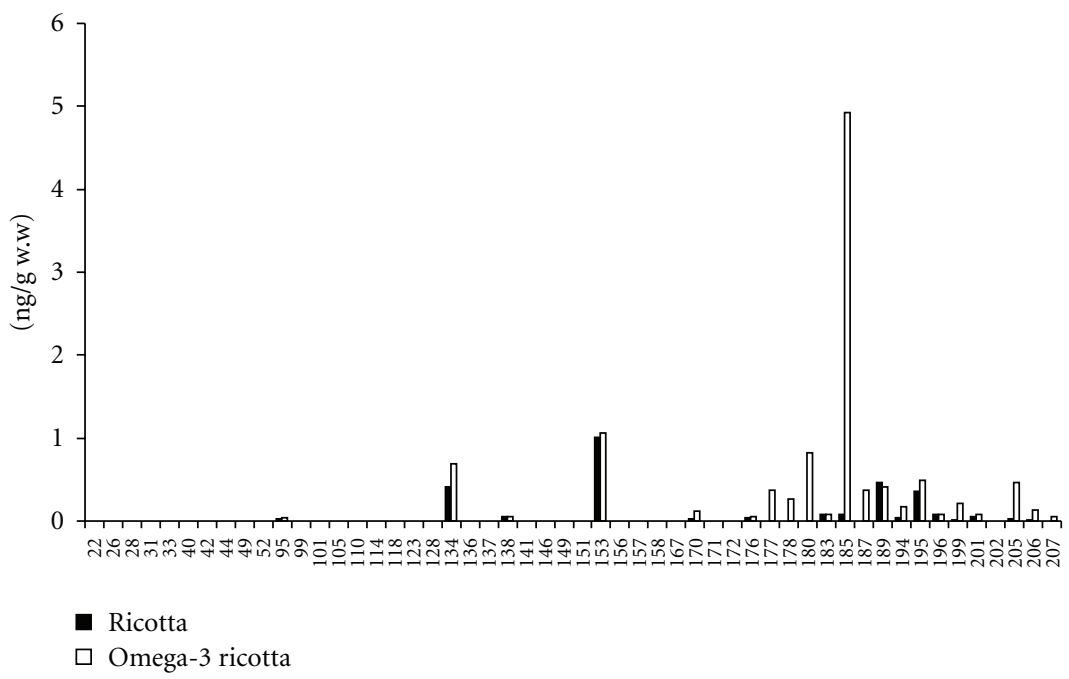

FIGURE 1: PCBs congener fingerprints in conventional samples of ricotta and omega-3-enriched ricotta.

7.1 (StatSoft Inc.), both for Windows XP. Results are given on a wet weight basis (w.w.) and on a lipid basis (l.b.). For calculations, concentrations below the LOD were considered as zero.

2.2. Quality Control. The accuracy of the analytical procedure was determined by analysis of certified materials from the National Institute of Standards and Technology, US Department of Commerce (Gaithersburg, Md, USA), the National Council of Canada, Institute for National Measurement Standards, and the Community Bureau of Reference (BCR). The following parameters/compounds were determined in the following materials: $\mathrm{HCB}$ and total DDTs in pig fat (NIST), fat content in homogenized meat (NIST); pesticides and total PCBs in cod liver oil (NIST), PCDD/F and PCBs in carp muscle (CARP-1, NRC), total PCBs and PBDE-47 in pig fat (ERM-IRMM), and total PCBs (BCR 450), PCDD, and PCDF (BCR RM 534) and pesticides (BCR 187) in powdered milk. Recovery was more than $88 \%$ in all cases. Recoveries were also evaluated by the method of additions at the time of extraction, using homogeneous replicates and were always greater than $90 \%$. A blank was analysed with every analysis series (five samples).

\section{Results and Discussion}

The samples had the following fat contents:

(i) semiskimmed milk 2.8-3.1\%,

(ii) "stracchino" (Italian soft cow cheese) 25.3-25.8\%,

(iii) "pecorino" (Italian sheep cheese) 23.5-24.0\%,

(iv) "ricotta" (Italian low-fat cheese) 15.8-16.1\%.

All classes of contaminants analysed were found in the samples (Tables 1 and 2). Means and standard deviations were calculated for each group of foods.

In almost all pools, the prevalent $\mathrm{PCB}$ congener was PCB153, followed by PCB-134 and PCB-189. Figure 1 shows an example of fingerprints of PCB congeners in conventional samples of ricotta and omega-3 ricotta: for the former, the prevalence ranking was the same as in most samples of conventional dairy products, whereas in the latter, high concentrations of PCB-185 and many other medium to highly chlorinated congeners, absent in conventional milk and dairy products, were found.

Among PCBs there was a prevalence of hexa- followed by hepta- and octachlorobiphenyls (39\%, 38\%, and 11\%, respectively, of mean total PCBs in all products). Trichlorobiphenyls were the lowest (1\%). Figure 2 shows the PCB isomer composition in the various dairy foods.

The most abundant DDT compound was $p p^{\prime}$-DDE (95\%), followed by $o p^{\prime}-\mathrm{DDE}(4 \%), o p^{\prime}-\mathrm{DDD}$, and $p p^{\prime}$-DDT $(<1 \%)$. The latter three compounds were found in a limited number of pools of samples. The prevalence of $p p^{\prime}-\mathrm{DDE}$, a metabolite of DDT degradation found in the environment [8], suggests direct ingestion and/or its accumulation in food chains, rather than exposure of the animal producing the milk to the compound [9].

PBDEs were found in cheese but never in milk. Tetraand pentabromide congeners such as PBDE-47 and PBDE99 were prevalent.

Among non-ortho-PCBs, congener 126 was prevalent, followed by 77 . Congeners 81 and 169 were never found. Among PCDFs and PDCCs, the latter was preponderant in all samples analysed.

TEQs were calculated on the basis of concentrations of PCDD, PCDF, and certain PCB congeners [10, 11]; none of the samples exceeded the WHO-TEQ 1998 safety limit adopted by the European Union (4 pg/g lipid basis, 1.b.).

The HCB levels encountered in the products can be compared with those reported by Leoni and colleagues [12] who found a range of $0.40-9.00 \mathrm{ng} / \mathrm{g}$ wet weight (w.w.), mean $3.15 \mathrm{ng} / \mathrm{g}$ w.w. in cheese, which is higher than our values (mean $1.67 \mathrm{ng} / \mathrm{g}$ w.w. in omega-3 and $0.14 \mathrm{ng} / \mathrm{g}$ w.w. in conventional products). This difference could be due to a reduction in levels of this contaminant since it was banned. Compared to our results, Kannan et al. [13] reported a lower 


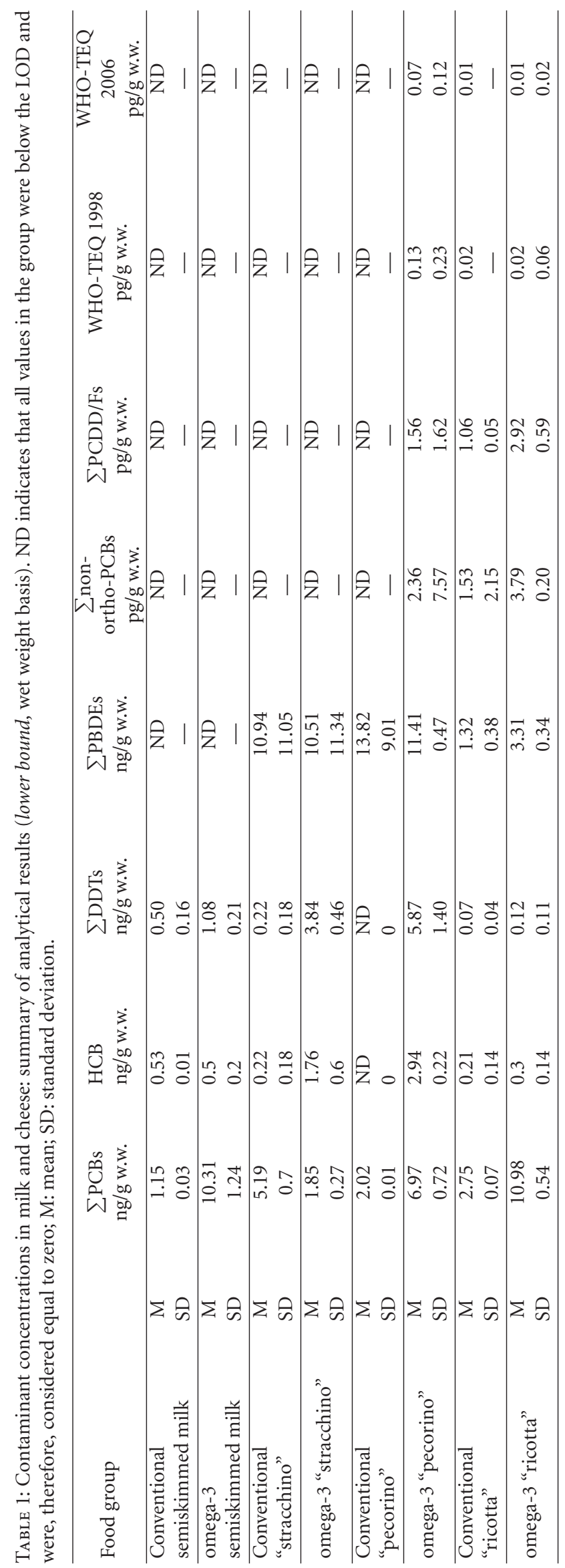




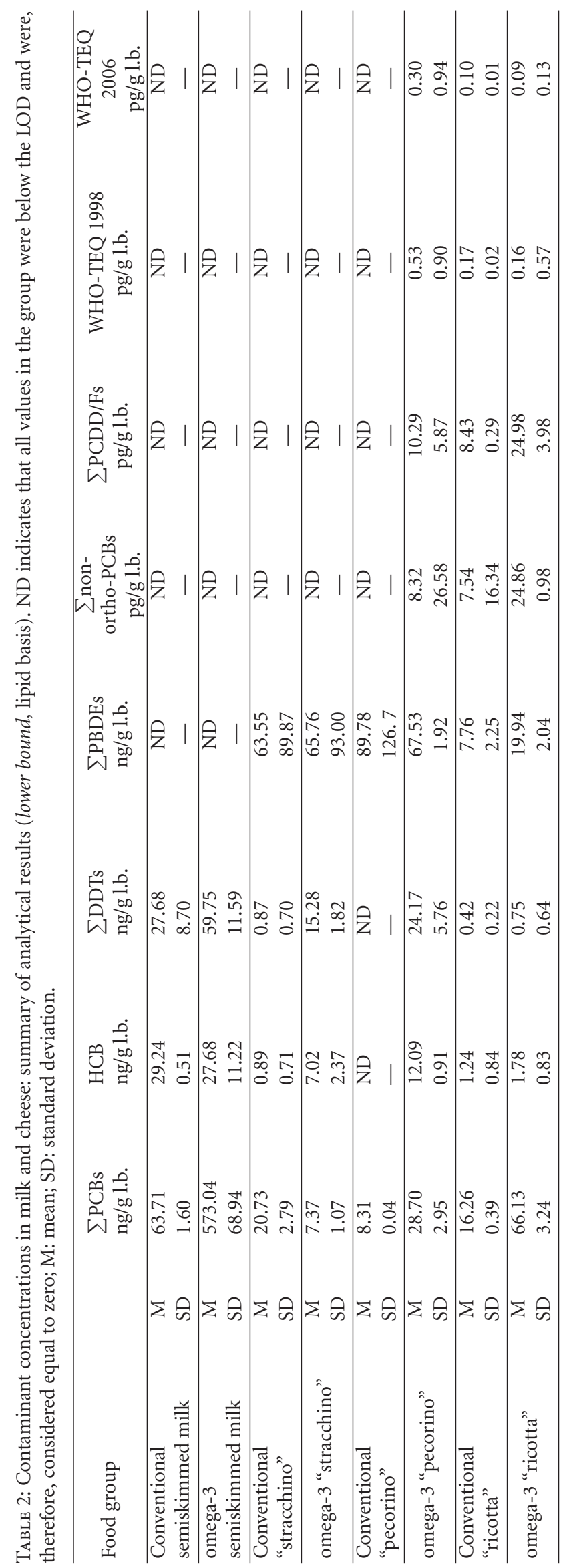


TABle 3: Mean concentrations of contaminants in milk reported by Kiviranta et al. [5] and Falcò et al. [6] on a wet weight basis, and mean \pm standard deviation by Schmid et al. [7] on a lipid basis. Data in ng/g for total PCBs, PBDE and HCB and in pg/g for the other contaminants/parameters.

\begin{tabular}{lcc}
\hline Kiviranta et al. [5] & Falcò et al. [6] & Schmid et al. [7] \\
\hline$\sum$ PCBs 2.6 & HCB 0.01 & WHO-TEQ 1998 0.59 \pm 0.22 \\
$\sum$ non-ortho-PCBs 2.1 & $\sum$ PCBs 1.28 & \\
$\sum$ PCDD/Fs 2.5 & $\sum$ PBDEs 0.04 & \\
\end{tabular}

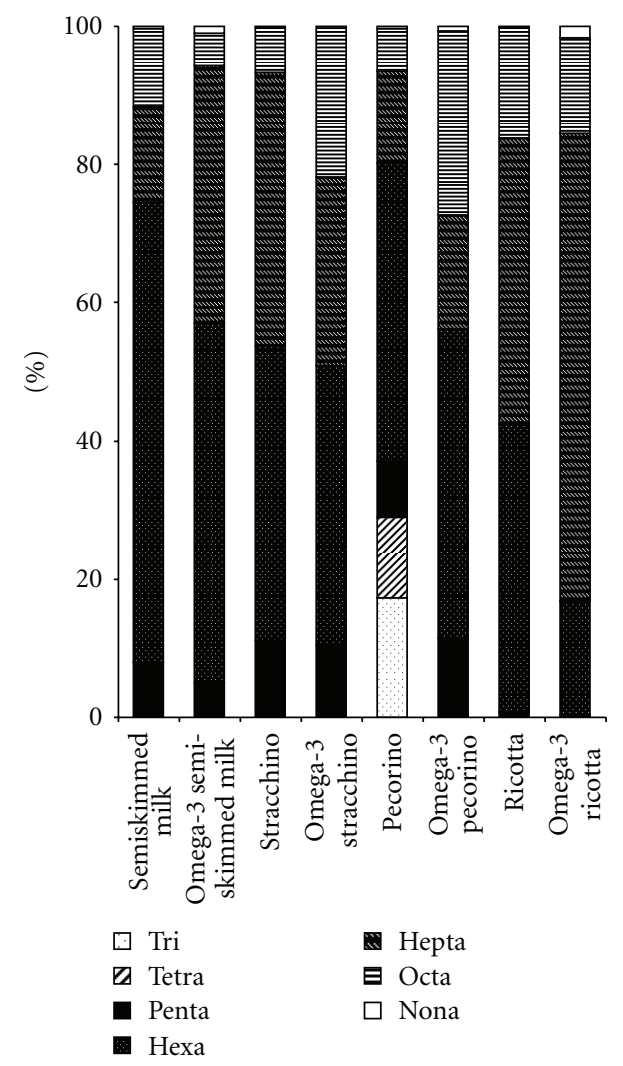

Figure 2: PCB isomer composition in the various dairy foods.

mean concentration of HCB in cheese from Moresby (Papua New Guinea): 0.43 ng/g w.w.

With regard to milk, our results can be compared to those of Kiviranta and colleagues [5], Schmid et al. [7], and Falcò et al. [6] for Finnish, Swiss, and Spanish milk samples (Table 3).

Application of the Mann-Whitney-Wilcoxon test to differences between values obtained for the pairs of foods by descriptive statistics, which showed that omega-3-enriched foods were more contaminated than conventional ones, confirmed this difference for $\sum$ PCBs, HCB, and $\sum$ DDT (W $=90, P=0.0103, \mathrm{~W}=92, P=0.0052$, and $\mathrm{W}=92, P=0.0052$, resp.).

\section{Conclusions}

Mean concentrations of the compounds analysed were clearly higher in omega-3-enriched products than in conventional ones. Specifically, differences in mean concentrations of PCBs, DDT, and HCB, all compounds, banned decades ago in Italy, were statistically significant, showing that the different levels of contamination were not due to normal variability of results but to actual addition of contaminants through addition of fish oil to milk and cheese.

The finding of higher levels of all contaminants in individual samples of omega-3-enriched foods sustains the hypothesis that these products may be more contaminated by lipophilic pollutants than traditional products. It would, therefore, be worthwhile doing a cost-benefit analysis of omega-3 dietary supplements which are certainly beneficial for the cardiovascular system but may simultaneously expose consumers to dangerous environmental contaminants.

\section{Abbreviations \\ DDT: dichlorodiphenyltrichloroethane HCB: hexachlorobenzene PBDEs: polybrominated diphenyl ethers PCBs: $\quad$ polychlorinated biphenyls PCDD/Fs: polychlorinated dibenzodioxins/furans.}

\section{Acknowledgments}

The authors acknowledge the Monte dei Paschi di Siena Foundation (Italy) for funding this research. They also thank Dr. Michela Mariottini (Environmental Sciences Department, University of Siena, Italy) for her generous help with GC/MS methods.

\section{References}

[1] A. Binelli and A. Provini, "POPs in edible clams from different Italian and European markets and possible human health risk," Marine Pollution Bulletin, vol. 46, no. 7, pp. 879-886, 2003.

[2] S. M. Waliszewski, V. T. Pardío, K. N. Waliszewski, J. N. Chantiri, and R. M. Infanzón, "Levels of organochlorine pesticides in Mexican butter," Journal of AOAC International, vol. 79, no. 3, pp. 784-786, 1996.

[3] A. K. D. Liem, "Dioxins and dioxin-like PCBs in foodstuffs. Levels and trends," Organoalogen Compounds, vol. 44, pp. 1-4, 1999.

[4] S. Corsolini, C. Guerranti, G. Perra, and S. Focardi, "Polybrominated diphenyl ethers, perfluorinated compounds and chlorinated pesticides in swordfish (Xiphias gladius) from the Mediterranean Sea," Environmental Science and Technology, vol. 42, no. 12, pp. 4344-4349, 2008. 
[5] H. Kiviranta, A. Hallikainen, M. L. Ovaskainen, J. Kumpulainen, and T. Vartiainen, "Dietary intakes of polychlorinated dibenzo-p-dioxins, libenzofurans and polychlorinated biphenyls in Finland," Food Additives and Contaminants, vol. 18, no. 11, pp. 945-953, 2001.

[6] G. Falcó, A. Bocio, J. M. Llobet, and J. L. Domingo, "Health risks of dietary intake of environmental pollutants by elite sportsmen and sportswomen," Food and Chemical Toxicology, vol. 43, no. 12, pp. 1713-1721, 2005.

[7] P. Schmid, E. Gujer, M. Zennegg, and C. Studer, “Temporal and local trends of PCDD/F levels in cow's milk in Switzerland," Chemosphere, vol. 53, no. 2, pp. 129-136, 2003.

[8] F. W. Kutz, P. H. Wood, and D. P. Bottimore, "Organochlorine pesticides and polychlorinated biphenyls in human adipose tissue," Reviews of Environmental Contamination and Toxicology, vol. 120, pp. 1-82, 1991.

[9] O. Tsydenova, T. B. Minh, N. Kajiwara, V. Batoev, and S. Tanabe, "Recent contamination by persistent organochlorines in Baikal seal (Phoca sibirica) from Lake Baikal, Russia," Marine Pollution Bulletin, vol. 48, no. 7-8, pp. 749-758, 2004.

[10] M. van den Berg, L. Birnbaum, A. T. C. Bosveld et al., "Toxic equivalency factors (TEFs) for PCBs, PCDDs, PCDFs for humans and wildlife," Environmental Health Perspectives, vol. 106, no. 12, pp. 775-792, 1998.

[11] M. van den Berg, L. S. Birnbaum, M. Denison et al., "The 2005 World Health Organization reevaluation of human and mammalian toxic equivalency factors for dioxins and dioxinlike compounds," Toxicological Sciences, vol. 93, no. 2, pp. 223241, 2006.

[12] V. Leoni, I. Camoni, G. Puccetti, A. Di Muccio, and L. Fabiani, "Estimate of the dose of chlorinated pesticides consumed daily by the Italian population (1978-1984)," Annali di Igiene: Medicina Preventiva e di Comunita, vol. 1, no. 3-4, pp. 433445, 1989.

[13] K. Kannan, S. Tanabe, R. J. Williams, and R. Tatsukawa, "Persistant organochlorine residues in foodstuffs from Australia, Papua New Guinea and the Solomon Islands: contamination levels and human dietary exposure," Science of the Total Environment, vol. 153, no. 1-2, pp. 29-49, 1994. 

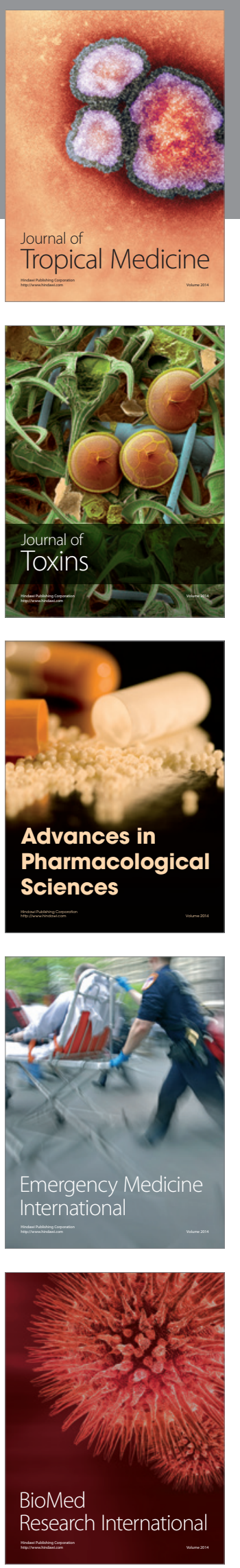
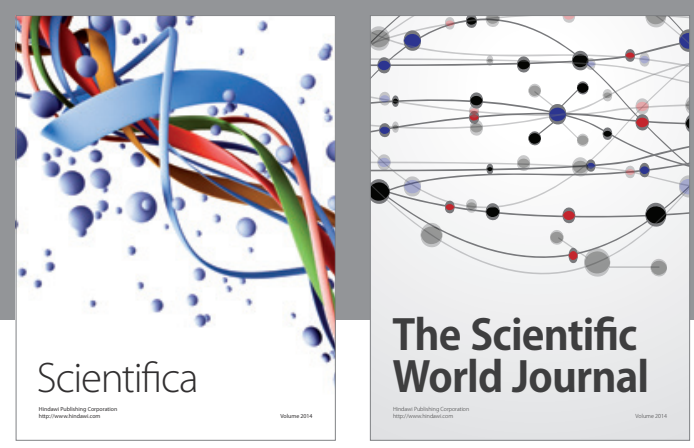

The Scientific World Journal
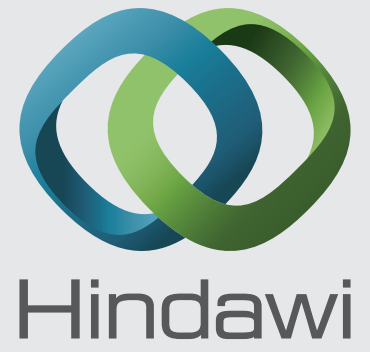

Submit your manuscripts at

http://www.hindawi.com
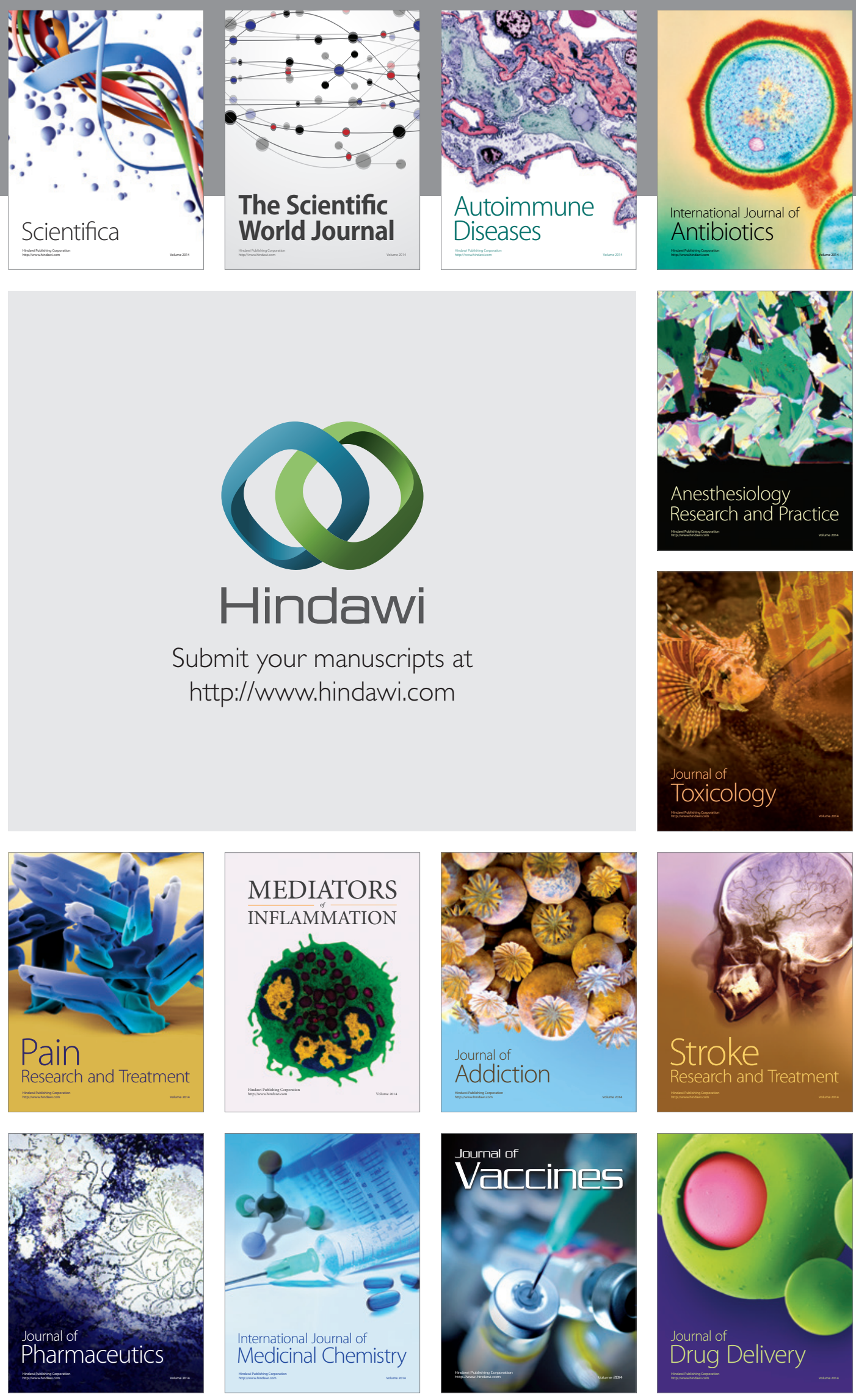